\title{
Efficacy of propiverine ER with or without $\alpha$-blockers related to maximum urinary flow rate in adult men with OAB: results of a 12-week, multicenter, non-interventional study
}

\author{
Matthias Oelke · Sandra Murgas • Ina Baumann • \\ Frieder Schnabel • Martin C. Michel
}

Received: 17 January 2011 / Accepted: 24 January 2011/Published online: 16 February 2011

(C) The Author(s) 2011. This article is published with open access at Springerlink.com

\begin{abstract}
Purpose Comparison of efficacy of propiverine extended release (ER) $30 \mathrm{mg}$ o.d. in the treatment of male OAB administered as monotherapy (MT) or add-on to $\alpha$-blockers (combination treatment, $\mathrm{CT}$ ) in relation to maximum urinary flow $\left(\mathrm{Q}_{\max }\right)$ in a non-interventional study.

Methods Men $\geq 40$ years with $\mathrm{OAB}$ symptoms, $\mathrm{Q}_{\max }$ $\geq 10 \mathrm{ml} / \mathrm{s}$, prostate volume $<40 \mathrm{ml}$, post-void residuals (PVR) $<100 \mathrm{ml}$, and IPSS $<20$ were included. OAB symptoms, IPSS, and PVR were recorded before and after 12 weeks of treatment. Participants were stratified by $\mathrm{Q}_{\max }$ (group $\mathrm{A} \geq 15 \mathrm{ml} / \mathrm{s}$, group $\mathrm{B}<15 \mathrm{ml} / \mathrm{s}$ ) and CT vs. MT. Safety parameters were monitored.

Results A total of 2,219 men participated and were involved in safety analysis; 1,849 men (mean age 66 years) fulfilled the inclusion criteria and were involved in efficacy analysis. In group A, 291 men received MT and 479 CT; in group B, 184 men received MT and 895 CT. OAB symptoms improved significantly in all groups throughout the study without differences between MT and CT. IPSS
\end{abstract}

M. Oelke $(\square)$

Department of Urology, Hannover Medical School,

Carl-Neuberg-Str. 1, 30625 Hannover, Germany

e-mail: oelke.matthias@mh-hannover.de

S. Murgas - F. Schnabel

APOGEPHA Arzneimittel GmbH, Dresden, Germany

I. Baumann

Surgery of Urology, Dresden, Germany

M. C. Michel

Department of Pharmacology and Pharmacotherapy,

Academic Medical Center, Amsterdam, The Netherlands improvement in group B was less with MT than with CT ( -3.9 vs. $-5.2 ; P<0.001)$, whereas IPSS improvement was similar in group A ( -4.6 vs. -5.1$)$. Mean PVR change was not clinically relevant, but two men $(0.1 \%)$ experienced urinary retention.

Conclusions Under real-life conditions, treatment of $\mathrm{OAB}$ symptoms with propiverine ER is equally effective in men with MT or CT regardless of baseline $\mathrm{Q}_{\max }$. In men with reduced $\mathrm{Q}_{\max }$, IPSS improvement is significantly smaller with MT. The incidence of urinary retention during propiverine ER treatment is low.

Keywords Lower urinary tract symptoms .

Overactive bladder syndrome - Cholinergic antagonists .

Adrenergic $\alpha$-antagonists - Urinary retention .

Propiverine hydrochloride
Abbreviations
BOO Bladder outlet obstruction
BPH Benign prostatic hyperplasia
CI Confidence interval
CT Combination therapy
(propiverine $+\alpha$-blocker)
ER Extended release
IPSS International prostate symptom score
ITT Intent-to-treat
LUTS Lower urinary tract symptoms
MT Monotherapy (propiverine)
NIS Non-interventional study
OAB Overactive bladder syndrome
o.d. Once daily
$\mathrm{Q}_{\max }$ Maximum urinary flow rate
(free uroflowmetry)
PSA Prostate-specific antigen
PVR Post-void residual urine 


\section{Introduction}

Men with lower urinary tract symptoms due to benign prostatic hyperplasia (LUTS-BPH) suffer to various degrees and severity of storage, voiding, and post-micturition symptoms [1]. Although voiding symptoms are more frequent, storage symptoms are more bothersome [1-3]. Storage symptoms comprise urgency, frequency, nocturia, and urgency urinary incontinence and are congruent with OAB [4]. Traditionally, BPH or related conditions were blamed for all LUTS in adult men; however, recent analyses demonstrated that $>50 \%$ of men with LUTS-BPH have no signs of $\mathrm{BOO}$ of which $>50 \%$ have $\mathrm{OAB}$ and urodynamically confirmed detrusor overactivity [5]. These men are often treated insufficiently with $\alpha$-blockers alone [6]. Although treatment of storage symptoms/OAB with antimuscarinics is effective in both genders, physicians are still reluctant to prescribe antimuscarinics in adult men due to the theoretical threat of increasing PVR or urinary retention.

Several randomized-controlled trials or cohort studies with antimuscarinics as monotherapy (MT) [7-11] or together with $\alpha$-blockers in combination therapy (CT) [12$18]$ in men have demonstrated that OAB symptoms and IPSS can be effectively reduced with antimuscarinics. The possible role of CT was mostly tested as add-on of the antimuscarinic to existing but insufficiently effective $\alpha$ blocker therapy, which makes it difficult to judge whether it indicated a benefit of CT or only demonstrated the efficacy of an antimuscarinic in $\alpha$-blocker non-responders. A pivotal study has applied the inclusion criteria of both classical LUTS-BPH and OAB studies and compared the effects of tamsulosin, tolterodine, and their combination with those of placebo [9]. With such inclusion criteria, either MT was only modestly effective when compared to placebo, whereas CT was effective against a range of symptoms.

Only one non-interventional study (NIS) has been published investigating tolterodine under real-life conditions in men with $\mathrm{OAB}$ and $\mathrm{Q}_{\max } \geq 15 \mathrm{ml} / \mathrm{s}$, thereby assuming nonobstructed BPH $[19,20]$. However, no real-life data are yet available for other antimuscarinics or adult men with decreased baseline $\mathrm{Q}_{\max }$. We, therefore, conducted a NIS in adult men with normal or reduced $\mathrm{Q}_{\max }$ using propiverine, a muscarinic receptor antagonist with additional calcium influx inhibitor [21] and $\alpha_{1}$-adrenoceptor blocking properties [22]. The aim of this trial was to evaluate in adult men with OAB whether (1) efficacy depends on baseline $\mathrm{Q}_{\max }$, (2) reduction in $\mathrm{OAB}$ symptoms with propiverine ER $30 \mathrm{mg}$ alone (MT) is as effective as with CT using propiverine ER $30 \mathrm{mg}$ together with $\alpha$-blockers, (3) reduction in overall symptoms, as measured by IPSS, is as effective with MT as with CT, and (4) treatment with propiverine ER $30 \mathrm{mg}$ is safe with regard to PVR and urinary retention.

\section{Patients and methods}

\section{Study design}

Between May 2008 and January 2009, 557 office-based urologists in Germany participated in this prospective NIS that consisted of three visits. At visit 1, the following parameters were recorded: demographic data, patient history (including previous or current diseases and medication), urinanalysis, 24-h bladder diary (urgency episodes, voiding frequency, nocturia, and incontinence episodes), IPSS (sum of answers to questions 1-7), $\mathrm{Q}_{\max }$ and voided volume during free uroflowmetry, and ultrasonic PVR as well as prostate volume measurements. At visits 2 and 3, after four and 12 weeks of treatment with propiverine ER, the variables of the bladder diary, IPSS, and PVR were recorded again. Additionally, patient-reported adverse events were documented. In Germany, approval for NIS by an ethic committee was not mandatory at this time.

\section{Inclusion and exclusion criteria}

Men aged $\geq 40$ years with $\mathrm{OAB}$ symptoms (urgency with or without urgency incontinence, frequency $>8 / 24 \mathrm{~h}$, nocturia $\geq 2 /$ night) were treated with propiverine ER $30 \mathrm{mg}$ o.d. alone (MT) or as add-on to existing treatment with $\alpha$ blockers (CT) if they met the following inclusion criteria: $\mathrm{Q}_{\max }: \geq 10 \mathrm{ml} / \mathrm{s}$ at voided volume $\geq 100 \mathrm{ml}, \mathrm{PVR}<100 \mathrm{ml}$, prostate volume $<40 \mathrm{ml}$, and IPSS $<20$. Exclusion criteria were the following: current or recurrent urinary tract infection, stress incontinence, catheterization, neurological history or neurogenic bladder dysfunction, history of lower urinary tract surgery within the last 6 months, use of $5 \alpha$ reductase inhibitors, bladder or prostate cancer, or interstitial cystitis/painful bladder syndrome.

\section{Efficacy and safety analyses}

OAB symptoms and IPSS were analyzed using the intentto-treat (ITT) population, defined as patients who met inclusion and exclusion criteria, received at least one dose of propiverine ER $30 \mathrm{mg}$, and had at least two visits. The ITT population was post hoc stratified by $\mathrm{Q}_{\max }(\geq 15 \mathrm{ml} / \mathrm{s}$ vs. $<15 \mathrm{ml} / \mathrm{s}$ ) and the use of MT vs. CT. All adverse events were monitored throughout the observational period (baseline to week 4 or 12). Patients who took at least one dose of propiverine were included in the safety analysis. 
Statistical analysis

For descriptive statistics, we report means with $95 \%$ confidence intervals. Significance of baseline-end data were calculated with the two-sided paired t-tests and intergroup analysis by independent samples t-test. A significance level of 5\% was applied for all statistical tests. Statistical analysis was performed with $\mathrm{SAS}^{\circledR}$ software (Cary, NC, USA).

\section{Results}

Study population

A total of 2,219 men participated in the study and were involved in safety analysis, of which 1,849 men $(83.3 \%)$ were included in the efficacy analysis. Baseline demographic and clinical data of the ITT population are shown in Table 1. Arterial hypertension (21.7\%) and diabetes mellitus $(12.2 \%)$ were the most common concomitant diseases and responsible for the majority of co-medications used prior to the study.

At study entry, 770 men $(41.6 \%)$ had $Q_{\max } \geq 15 \mathrm{ml} / \mathrm{s}$ (group A) and 1,079 men (58.4\%) had $\mathrm{Q}_{\max }<15 \mathrm{ml} / \mathrm{s}$ (group B). In group A, 291 (37.8\%) and 479 men $(62.2 \%)$ received $\mathrm{MT}$ and $\mathrm{CT}$, respectively. In group $\mathrm{B}, 184$ men (17.1\%) had MT and 895 CT (82.9\%). Tamsulosin was the most commonly used $\alpha$-blocker $(79.9 \%)$, followed by alfuzosin (13.2\%). Patients in group B were significantly older, had greater prostate volumes and PVR, more incontinence episodes, higher voiding frequencies and nocturia, and lower voided volumes (Table 1). IPSS and urgency episodes were comparable between the group A and $\mathrm{B}$.
Efficacy analysis

\section{Diary variables}

Significant improvements from baseline to study end were demonstrated for all variables of the bladder diary. For the overall ITT population, the number of 24-h urgency episodes declined from 9.4 to 2.8 (mean change $-6.4 /-68 \%$ ), 24-h incontinence episodes from 2.0 to 0.3 (mean change $-1.7 /-85 \%)$, 24-h voiding frequency from 13.5 to 8.1 (mean change $-5.4 /-40 \%$ ), and nocturia from 3.5 to 1.5 (mean change $-2.1 /-60 \%$ ). The proportion of incontinent men decreased from $58.2 \%$ at beginning of the study to $15.3 \%$ at study end. There were no statistical differences between the outcomes of group A and B as well as between MT and CT (Table 2).

\section{IPSS}

Total IPSS decreased significantly from beginning of the study to week 12 in all four patient groups. While men in group A exhibited similar efficacy with MT (-4.6) and CT $(-5.1)$, patients in group B with MT reported a significantly smaller IPSS improvement than with CT (-3.7 vs. -5.3; Fig. 1).

\section{Uroflowmetry}

No significant change in $\mathrm{Q}_{\max }$ was observed within group A $(0 \mathrm{ml} / \mathrm{s}$ with MT vs. $+0.2 \mathrm{ml} / \mathrm{s}$ with $\mathrm{CT} ; P=0.768)$ or group B $(+2.7 \mathrm{ml} / \mathrm{s}$ with $\mathrm{MT}$ vs. $+3.4 \mathrm{ml}$ with $\mathrm{CT}$; $P=0.063$ ). However, $\mathrm{Q}_{\max }$ was significantly different between the treatment regimes when group A was compared with group B $(P<0.001)$.

Table 1 Baseline and clinical data of all patients of the ITT population and comparison between group A ( $\left.\mathrm{Q}_{\max } \geq 15 \mathrm{ml} / \mathrm{s}\right)$ and group B $\left(\mathrm{Q}_{\max }<15 \mathrm{ml} / \mathrm{s}\right)$; values given as means and $95 \%$ confidence intervals $(95 \% \mathrm{CI})$

\begin{tabular}{|c|c|c|c|c|}
\hline Parameter & $\begin{array}{l}\text { All participants } \\
(n=1,849)\end{array}$ & $\begin{array}{l}\text { Group A } \\
(n=770)\end{array}$ & $\begin{array}{l}\text { Group B } \\
(n=1,079)\end{array}$ & $\begin{array}{l}P \text {-value } \\
(\text { Group A vs. B) }\end{array}$ \\
\hline Mean age (years) & $66.0(65.6-66.5)$ & $64.3(63.6-65.0)$ & $67.3(66.7-67.8)$ & $<0.001$ \\
\hline IPSS & $16.9(16.4-17.2)$ & $16.6(16.2-16.9)$ & $17.2(16.7-17.6)$ & 0.706 \\
\hline Prostate volume (ml) & $37.2(36.6-37.7)$ & $34.9(34.1-35.8)$ & $38.7(38.0-39.4)$ & $<0.001$ \\
\hline $\mathrm{Q}_{\max }(\mathrm{ml} / \mathrm{s})^{\dagger}$ & $14.8(14.5-15.1)$ & $19.4(18.8-20.0)$ & $11.5(11.4-11.6)$ & Not applicable \\
\hline Voided volume $(\mathrm{ml})^{\dagger}$ & 209 (206-212) & $223(218-229)$ & $199(195-203)$ & $<0.001$ \\
\hline Post-void residual urine $(\mathrm{ml})$ & $36(34-37)$ & $28(26-30)$ & $41(39-43)$ & $<0.001$ \\
\hline Urgency episodes/24 h (n) & $9.4(9.1-9.6)$ & $9.7(9.3-10.2)$ & $9.1(8.8-9.4)$ & 0.099 \\
\hline Incontinence episodes/24 h ( $(n)$ & $2.0(1.9-2.2)$ & $1.9(1.7-2.1)$ & $2.1(2.0-2.3)$ & 0.001 \\
\hline Voiding frequency/24 h $(n)$ & $13.5(13.3-13.7)$ & $13.4(13.1-13.6)$ & $13.6(13.3-13.8)$ & 0.025 \\
\hline Nocturia $(n)$ & $3.5(3.5-3.6)$ & $3.4(3.3-3.5)$ & $3.7(3.5-3.8)$ & 0.005 \\
\hline
\end{tabular}

$Q_{\max }$ Maximum urinary flow rate, IPSS International Prostate Symptom Score

$\dagger$ Obtained by free uroflowmetry

Significant values are indicated in bold 


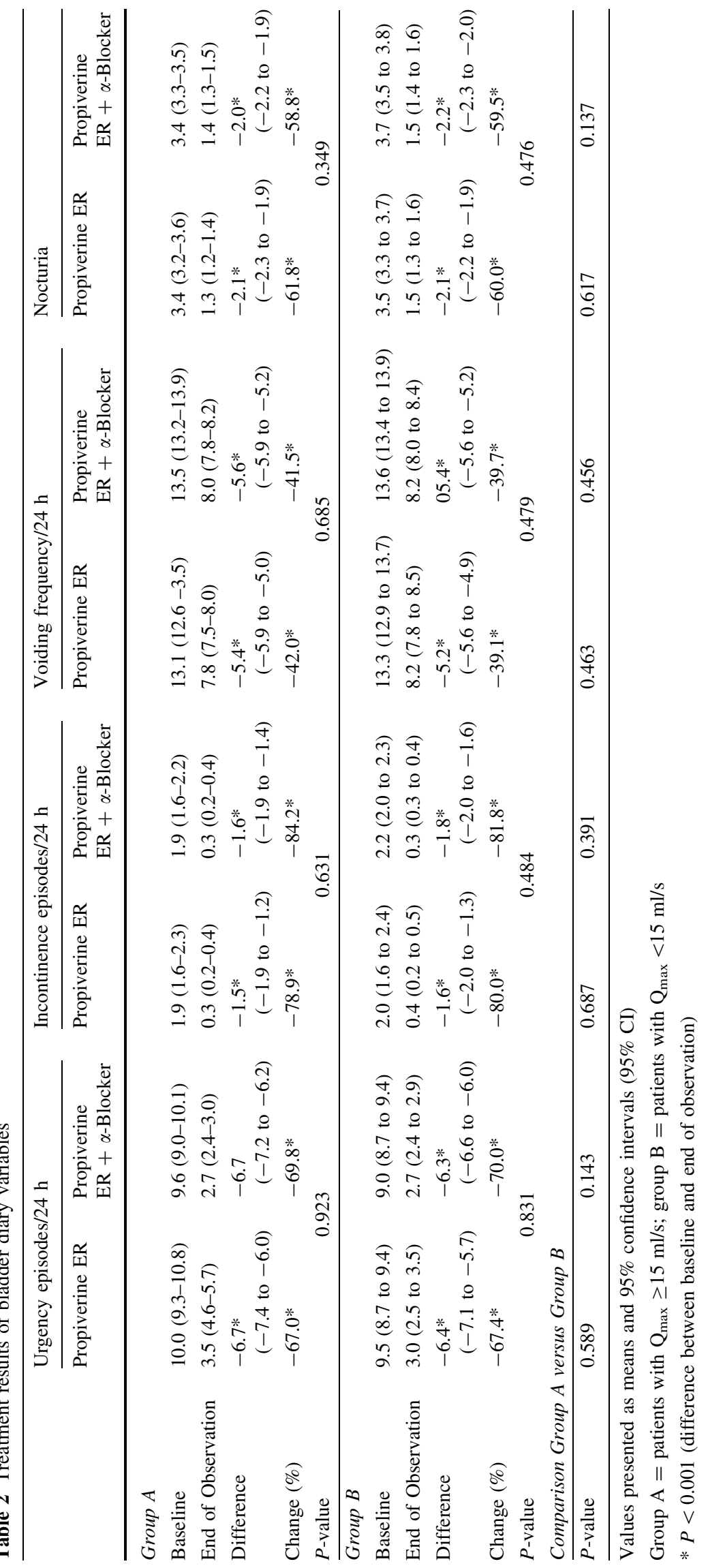




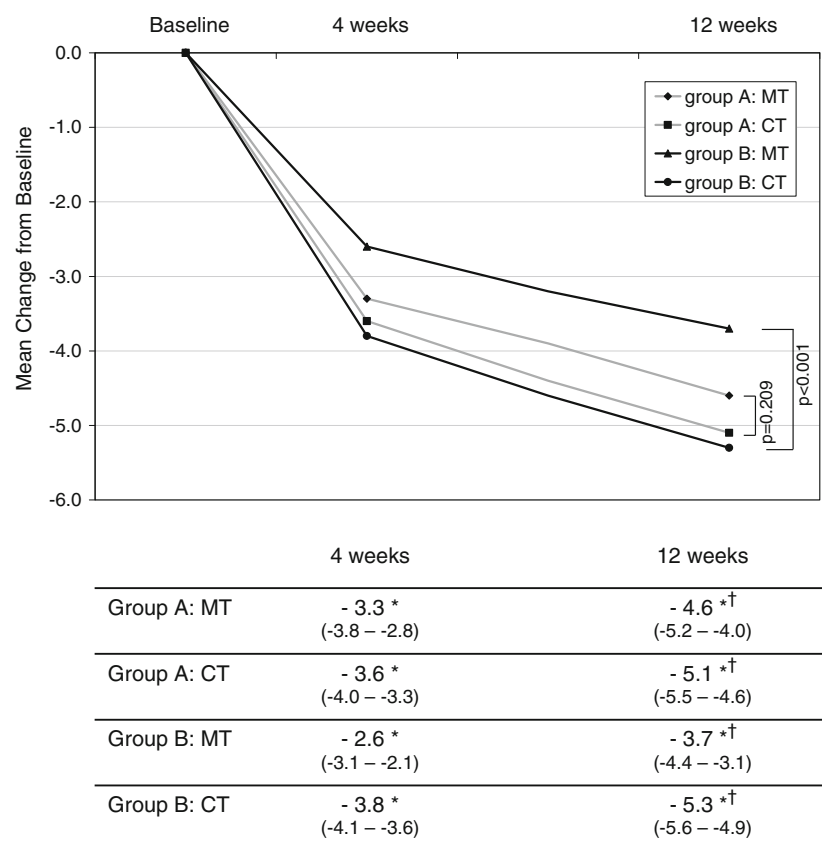

Fig. 1 Mean absolute IPSS changes from baseline to end of observation in group A (gray lines) and group B (black lines), *significant against baseline $(P<0.001)$, significant difference between treatment week 4 and $12(P<0.001)$

In group $\mathrm{A}$, mean voided volumes increased by 40 and $46 \mathrm{ml}$ with MT and CT, respectively $(P=0.301)$. In group $\mathrm{B}$, mean voided volume increased by 35 and $52 \mathrm{ml}$ with MT and CT, respectively, but the increase was significantly higher for CT $(P<0.001)$.

\section{Safety and tolerability analysis}

\section{Post-void residual volume or urinary retention}

Mean PVR change was not clinically relevant during the treatment period. At week 12, mean PVR decreased to $22 \mathrm{ml}$ in group $\mathrm{A}(-6 \mathrm{ml})$ and $27 \mathrm{ml}$ in group $\mathrm{B}(-15 \mathrm{ml})$. Despite the overall reduction in mean PVR, 412 patients (18.6\%) of the safety population had PVR increase (mean +19 ml, range 5-250 ml) including 154 men (6.9\%) with PVR increase of $\geq 20 \mathrm{ml}$ (mean increase $+35 \mathrm{ml}$, mean PVR: $57 \mathrm{ml}$ ) but only two men experienced acute urinary retention requiring catheterization (one with $\mathrm{CT}$ and baseline $\mathrm{Q}_{\max } 15.0 \mathrm{ml} / \mathrm{s}$; the other with MT and baseline $\left.\mathrm{Q}_{\max } 9.0 \mathrm{ml} / \mathrm{s}\right)$.

\section{Treatment discontinuation and adverse events}

Two thousand and seventy patients $(93.3 \%)$ completed the study. Sixty men (2.7\%) were lost to follow-up and $89(4 \%)$ discontinued the study. The reasons for premature treatment termination were insufficient efficacy $(1.1 \%)$, adverse events
$(0.9 \%)$, or patient desire $(0.8 \%)$. Ten men $(0.5 \%)$ with increased PVR (mean baseline PVR $50 \mathrm{ml}$ and increase to $125 \mathrm{ml}$ during the first 4 weeks) and two men $(0.1 \%)$ with urinary retention also discontinued the treatment.

Adverse drug reactions were reported by 108 patients $(4.9 \%)$ of which xerostomia $(3.6 \%)$, constipation $(0.9 \%)$, dizziness $(0.3 \%)$, and accommodation disorder $(0.3 \%)$ occurred most frequently.

\section{Discussion}

Although it often remains unclear in clinical practice whether male LUTS are caused by BPH and/or OAB, convincing evidence has accumulated that men can benefit from antimuscarinics, particularly when storage symptoms dominate and/or insufficient treatment response has been obtained by prior $\alpha$-blocker treatment. Key questions for clinical practice are who benefits from an antimuscarinic, who from $\alpha$-blocker, and who from CT? The presence of BOO may be one criterion to make this choice, particularly because it remains unclear whether the fear of urinary retention by exposing men with enlarged prostates to antimuscarinics is warranted. Therefore, we have explored in a real-life setting whether efficacy of propiverine differs between men with $\geq 15 \mathrm{ml} / \mathrm{s}$ and $<15 \mathrm{ml} / \mathrm{s}$ and how this is affected by MT and CT.

\section{Critique of methods}

NIS and randomized-controlled trials have distinct advantages and disadvantages. While controlled trials have high internal validity due to randomization, blinding, and, in most cases, source data monitoring, they have limited external validity because they typically recruit somewhat artificial populations due to their strict inclusion and exclusion criteria. In contrast, NIS have limited internal validity due to their lack of a control group but have a greater external validity because they have less rigorous inclusion and exclusion criteria and, hence, are more representative for patients receiving treatment in real practice. Therefore, NIS cannot substitute for controlled trials but rather provide complementary evidence. A NIS cannot provide information on the absolute efficacy or safety of a drug and such data have already been reported for propiverine from randomized-controlled trials [23].

$\mathrm{Q}_{\max }$ assessment does not substitute for a vigorous BOO evaluation by pressure-flow studies but remains the main approach in routine practice. While $\mathrm{Q}_{\max } \geq 15 \mathrm{ml} / \mathrm{s}$ reflects an absence of $\mathrm{BOO}$ in $97 \%$ of patients, men with $\mathrm{Q}_{\max }<10 \mathrm{ml} / \mathrm{s}$ have bladder dysfunction due to different causes, e.g. detrusor underactivity or, in 69\%, BOO [24]. $\mathrm{Q}_{\max } 10-14.9 \mathrm{ml} / \mathrm{s}$ is more difficult to interpret as it may or 
may not indicate BOO. For safety reasons and in line with the summary of product characteristics of propiverine, we defined $\mathrm{Q}_{\max }<10 \mathrm{ml} / \mathrm{s}$ as well as limits for PVR and prostate volume as exclusion criteria in our study. Therefore, our patient stratification primarily compared men with $\geq 15$ versus those with $10-14.9 \mathrm{ml} / \mathrm{s}$ as a necessary compromise between scientific desirability and practical feasibility in a NIS, generating a comparison of men unlikely to have $\mathrm{BOO}$ versus those at risk of $\mathrm{BOO}$.

\section{Baseline data}

Baseline data of the present study are very similar to those found in NIS with other antimuscarinics performed in Germany [19, 25-27], indicating that our patients are representative for those typically seen by German urologists.

Given that $\mathrm{Q}_{\max }$ decreases and prostate size, IPPS, and incontinence episodes increase with age, it is not surprising that our two main groups of patients defined by their $\mathrm{Q}_{\max }$ differed somewhat by age, prostate size, or incontinence episode frequency. However, these differences were surprisingly small. Therefore, we chose to present direct group comparisons for treatment effects rather than applying multiple regression models with one or more of those variables as additional explanatory variables.

\section{Treatment effects}

The overall efficacy of propiverine ER in the present NIS in men was similar to efficacy reported with propiverine immediate release in a mixed gender population under controlled conditions. The key finding of our study is that propiverine improved storage symptoms similarly in men with $\mathrm{Q}_{\max } \geq 15$ or $10-14.9 \mathrm{ml} / \mathrm{s}$ and $\mathrm{MT}$ or add-on to existing $\alpha$-blocker treatment. The group with lower $\mathrm{Q}_{\max }$ may comprise men with low-grade BOO and/or with detrusor underactivity [24]. On mechanistic grounds, lowgrade $\mathrm{BOO}$ is unlikely to affect $\mathrm{OAB}$ improvement by antimuscarinics. Detrusor underactivity could impair efficacy of an antimuscarinic in a smooth muscle-centric view but recent evidence suggests that antimuscarinics act in part via the urothelium and/or afferent nerves [28]. While the present data are unsuitable to prove that point, they certainly are in line with this view.

Perhaps even more interesting is the similar efficacy of propiverine against OAB symptoms when used as MT or add-on to $\alpha$-blocker treatment. In men with LUTS-BPH, $\alpha$ blockers are effective against storage symptoms at group level [3]. The fact that propiverine patients in the CT group received antimuscarinics as add-on indicates that this group may represent relative non-responders to $\alpha$-blockers, a situation where efficacy of an antimuscarinic is likely. Noteworthy, the only relevant exception from the similar efficacy of propiverine in MT and CT is the small, but still significant improvement of IPSS in CT of men with $\mathrm{Q}_{\max }$ $<15 \mathrm{ml} / \mathrm{s}$. At present, we have no good explanation for this finding but it is in line with studies demonstrating that CT is superior to both antimuscarinic and $\alpha$-blocker MT in reducing IPSS [9].

The overall tolerability in our study was very good, and adverse drug reactions were reported less frequently than in randomized-controlled trials with propiverine [23]. This situation is typical for NIS and has also been observed with other antimuscarinics [19, 25-27]. A key safety consideration in the use of antimuscarinics in elderly men is the possible risk of inducing increased PVR/urinary retention. A meta-analysis showed an incidence of urinary retention while antimuscarinic treatment in men of $0.8 \%$ [29]. In line with previous controlled studies with propiverine [12, 13, 18], the observed changes in PVR were small and acute urinary retention occurred only rarely in the present study. This may at least in part be attributable to study design that excluded men with the largest risk, i.e. those with $\mathrm{BOO}$ and risk factors, such as existing large PVR or prostates for safety reasons and in line with the drug label. Moreover, it is a general impression that retention occurs less frequently when antimuscarinics are used as add-on to existing $\alpha$ blocker treatment, probably because $\alpha$-blockers per se reduce the risk of retention in studies up to one year [30]. In this regard, the recently demonstrated $\alpha_{1}$-adrenoceptor antagonist properties of propiverine [22] may also have contributed to the low observed incidence of retention.

\section{Conclusions}

Under real-life conditions, the efficacy of propiverine against storage symptoms is similar in men with $\mathrm{Q}_{\max }$ $10-14.9$ and $\geq 15 \mathrm{ml} / \mathrm{s}$ and independent of the use of MT or add-one use to existing $\alpha$-blocker treatment. However, overall IPSS improvement, at least in some groups of men, may be better with CT than propiverine MT. When certain safety considerations are followed $\left(\mathrm{Q}_{\max } \geq 10 \mathrm{ml} / \mathrm{s}\right)$, propiverine ER with or without concomitant $\alpha$-blockers causes only small if any PVR increases and has a very low risk of urinary retention.

Open Access This article is distributed under the terms of the Creative Commons Attribution Noncommercial License which permits any noncommercial use, distribution, and reproduction in any medium, provided the original author(s) and source are credited.

Conflict of interest MO has received lecturer and/or consultant honoraria in the antimuscarinic field from Apogepha, Astellas, Bayer, Pfizer, Pohl-Boskamp, and Teva. SM and FS are employees of Apogepha Arzneimittel GmbH, Dresden, Germany. IB has received a lecturer honorarium from Apogepha, Astellas, Bayer, Pfizer, Schwarz, and UCB-Pharma. MCM has received lecturer and/or consultant 
honoraria in the antimuscarinic field from Allergan, Astellas, Bayer, Pfizer, Schwarz Pharma, and Theravance.

\section{References}

1. Sexton CC, Coyne KS, Kopp ZS, Irwin DE, Milson I, Aiyer LP, Tubaro A, Chapple CR, Wein AJ (2009) The overlap of storage, voiding and postmicturition symptoms and implications for treatment seeking in the USA, UK and Sweden: EpiLUTS. BJU Int 103(Suppl 3):12-23

2. Peters TJ, Donovan JL, Kay HE, Abrams P, de la Rosette JJ, Porru D, Thüroff JW (1997) The International Continence Society "Benign Prostatic Hyperplasia" Study: the bothersomeness of urinary symptoms. J Urol 157:885-889

3. Sountoulides P, van Dijk MM, Wijkstra H, de la Rosette JJ, Michel MC (2010) Role of voiding and storage symptoms for the quality of life before and after treatment in men with voiding dysfunction. World J Urol 28:3-8

4. Abrams P, Cardozo L, Fall M, Griffiths D, Rosier P, Ulmstein U, van Kerrebroeck P, Victor A, Wein A (2002) The standardisation of terminology of lower urinary tract function: report from the standardisation sub-committee of the International Continence Society. Neurourol Urodyn 21:167-178

5. Oelke M, Baard J, Wijkstra H, de la Rosette JJ, Jonas U, Höfner K (2008) Age and bladder outlet obstruction are independently associated with detrusor overactivity in patients with benign prostatic hyperplasia. Eur Urol 54:419-426

6. Novara G, Galfano A, Ficarra V, Artibani W (2006) Anticholinergic drugs in patients with bladder outlet obstruction and lower urinary tract symptoms: a systematic review. Eur Urol 50:675-683

7. Roehrborn CG, Abrams P, Rovner ES, Kaplan SA, Herschorn S, Guan Z (2006) Efficacy and tolerability of tolterodine extendedrelease in men with overactive bladder and urgency incontinence. BJU Int 97:1003-1006

8. Kaplan SA, Roehrborn CG, Dmochowski R, Rovner ES, Wang JT, Guan Z (2006) Tolterodine extended release improves overactive bladder symptoms in men with overactive bladder and nocturia. Urology 68:328-332

9. Kaplan SA, Roehrborn CG, Rovner ES, Carlsson M, Bavendam T, Guan Z (2006) Tolterodine and tamsulosin for treatment of men with lower urinary tract symptoms and overactive bladder. JAMA 296:2319-2328

10. Dmochowski R, Abrams P, Marschall-Kehrel D, Wang JT, Guan Z (2007) Efficacy and tolerability of tolterodine extended release in male and female patients with overactive bladder. Eur Urol 51:1054-1064

11. Herschorn S, Jones JS, Oelke M, MacDiarmid S, Wang JT, Guan Z (2010) Efficacy and tolerability of fesoterodine in men with overactive bladder: a pooled analysis of 2 phase III studies. Urology 75:1149-1155

12. Saito H, Yamada T, Oshima H, Morita T, Mizuo T, Takeuchi S, Ando M, Sekine H (1999) A comparative study of the efficacy and safety of tamsulosin hydrochloride alone and in combination of propiverine hydrochloride in the benign prostatic hypertrophy with pollakisuria and/or urinary incontinence. Jap J Urol Surg 12:525-536

13. Lee KS, Choo MS, Kim DY, Kim JC, Kim HJ, Min KS, Lee JB, Jeong HJ, Lee T, Park WH (2005) Combination treatment with propiverine hydrochloride plus doxazosin controlled release gastrointestinal therapeutic system formulation for overactive bladder and coexisting benign prostatic obstruction: a prospective, randomized, controlled multicenter study. J Urol 174:13341338
14. MacDiarmid SA, Peters KM, Chen A, Armstrong RB, Orman C, Aquilina JW, Nitti VW (2008) Efficacy and safety of extendedrelease Oxybutynin in combination with tamsulosin for treatment of lower urinary tract symptoms in men: randomized, doubleblind, placebo-controlled study. Mayo Clin Proc 83:1002-1010

15. Kaplan SA, Walmsley K, Te AE (2005) Tolterodine extended release attenuates lower urinary tract symptoms in men with benign prostatic hyperplasia. J Urol 174:2273-2276

16. Yang Y, Zhao SF, Li HZ, Wang W, Zhang Y, Xiao H, Zhang X (2007) Efficacy and safety of combined therapy with terazosin and tolterodine for patients with lower urinary tract symptoms associated with benign prostatic hyperplasia: a prospective study. Chin Med J 120:370-374

17. Kaplan SA, McCammon K, Fincher R, Fakhoury A, He W (2009) Safety and tolerability of solifenacin add-on therapy to $\alpha$-blocker treated men with residual urgency and frequency. J Urol 182:2825-2830

18. Nishizawa O, Yamaguchi O, Takeda M, Yokoyama O (2011) Randomized controlled trial to treat benign prostatic hyperplasia with overactive bladder using an alpha-blocker combined with anticholinergics. LUTS doi:10.1111/j.1757-5672.2010.00081.x

19. Höfner K, Burkart M, Jacob G, Jonas U (2007) Safety and efficacy of tolterodine extended release in men with overactive bladder symptoms and presumed non-obstructive benign prostatic hyperplasia. World J Urol 25:627-633

20. Höfner K, Burkart M, Jacob G, Jonas U (2010) Symptomatic and quality of life response to tolterodine in subgroups of men with overactive bladder symptoms and presumed non-obstructive benign prostatic hyperplasia. World J Urol 28:353-357

21. Wuest M, Hecht J, Christ T, Braeter M, Schoeberl C, Hakenberg OW, Wirth MP, Ravens U (2005) Pharmocodynamics of propiverine and three of its main metabolites on detrusor contraction. Br J Pharmacol 145:608-619

22. Wuest M, Witte LP, Michel-Reher MB, Propping S, Braeter M, Strugala G, Wirth M, Michel MC, Ravens U (2011) The muscarinic receptor antagonist propiverine exhibits $\alpha_{1}$-adrenoceptors antagonism in human prostate and porcine trigonum. World $\mathrm{J}$ Urol. doi:10.1007/s00345-011-0655-6

23. Jünemann KP, Hessdörfer E, Unamba-Oporah I, Berse M, Brünjes R, Madersbacher H, Gramatte T (2006) Propiverine hydrochloride immediate and extended release: comparison of efficacy and tolerability in patients with overactive bladder. Urol Int 77:334-339

24. Oelke M, Höfner K, Jonas U, de la Rosette JJ, Ubbink DT, Wijkstra H (2007) Diagnostic accuracy of noninvasive tests to evaluate bladder outlet obstruction in men: detrusor wall thickness, uroflowmetry, postvoid residual urine, and prostate volume. Eur Urol 52:827-834

25. Michel MC, de la Rosette JJ, Piro M, Goepel M (2004) Does concomitant stress incontinence alter the efficacy of tolterodine in patients with overactive bladder? J Urol 172:601-604

26. Witte LP, Peschers U, Vogel M, de la Rosette JJ, Michel MC (2009) Does the number of previous deliveries affect overactive bladder symptoms and their response to treatment? LUTS 1:82-87

27. Schneider T, Marschall-Kehrel D, Hanisch JU, Michel MC (2010) Do gender, age or lifestyle factors affect responses to antimuscarinic treatment in overactive bladder patients? Int J Clin Pract 64:1287-1293

28. Yamaguchi $O$ (2010) Antimuscarinics and overactive bladder: other mechanism of action. Neurourol Urodyn 29:112-115

29. Blake-James BT, Rashidian A, Ikeda Y, Emberton M (2007) The role of anticholinergics in men with lower urinary tract symptoms suggestive of benign prostatic hyperplasia: a systematic review and meta-analysis. BJU Int 99:85-96

30. Michel MC, Goepel M (2001) Lower urinary tracts symptoms suggestive of benign prostatic obstruction: what's the long-term effectiveness of medical therapies? Eur Urol. 39(Suppl 3):20-5 